\title{
Electromagnetic Radiation
}

National Cancer Institute

\section{Source}

National Cancer Institute. Electromagnetic Radiation. NCI Thesaurus. Code C17050.

The radiation of energy as transverse waves produced by moving charges. 